\title{
Group A Rotaviruses Produce Extrahepatic Biliary Obstruction in Orally Inoculated Newborn Mice
}

\author{
MARIE RIEPENHOFF-TALTY, KNUT SCHAEKEL. H. FRED CLARK, WOLFGANG MUELLER. \\ INGRID UHNOO. THOMAS ROSSI. JOHN FISHER. AND PEARAY L. OGRA
}

\begin{abstract}
Department of Pediatrics [M.R.-T., T.R., J.F.J. Microbiologv [M.R.-T.], and Pathology [J.F.]. School of
Medicine, State University of New York at Buffalo, Division of Infectious Diseases [M.R.-T., K.S./ and Gastroenterology [T.R.]. The Children's Hospital, Buffalo. New York 14222: Department of Pediatrics. Universit of Pennsylvania, and Division of Infectious Diseases, Children's Hospital [H.F.C.J. Philadelphia. Pennsvlvania 19104: Department of Pediatrics, Medizinische Hochschule Hannover Kinderklinik [W.M.]. Hannover. Germany: Department of Pediatrics and Division of Infectious Diseases, University Hospital [I.U.J. Uppsala. Sweden: and Department of Pediatrics, University of Texas Medical Branch /P.L.O.J. Galveston. Texas 77555
\end{abstract}

\begin{abstract}
Extrahepatic biliary atresia is a devastating disease occurring in 1 in 10000 to 14000 infants annually in the United States. We have recently described preliminary data suggesting an association of group $\mathrm{C}$ rotavirus with biliary atresia in two infants. However, a group $\mathrm{C}$ rotavirus animal model of biliary atresia is not presently available. On the other hand, some strains of the bettercharacterized and much more common group A rotaviruses produce hepatobiliary disease in infant mice. This disease shares many characteristics of the human infection. The present report describes extrahepatic biliary obstruction in immunocompetent $\mathrm{BALB} / \mathrm{c}$ infant mice infected with a human or animal strain of group A rotavirus. Two-d-old BALB/c mice orally inoculated with hepatobiliary tropic rotavirus were shown to have active virus replication in the biliary tract and liver as early as $48 \mathrm{~h}$ postinoculation. At approximately $7 \mathrm{~d}$ postinoculation, between one fourth and one half of infant mice, depending on the virus strain, showed signs of inflammation and swelling in the bile ducts. The obstruction was complete in about one half of symptomatic animals. Although there was no obvious atresia as described in human infants, the obstruction was irreversible about $50 \%$ of the time, and the resulting fibrosis and bile ductular proliferation in the liver were strikingly similar to those seen in the liver of the human infant with biliary atresia. (Pediatr Res 33: 394-399, 1993)
\end{abstract}

\section{Abbreviations}

EHBA, extrahepatic biliary atresia pi, postinoculation

RRV, rhesus rotavirus

$\mathrm{H} \times \mathrm{E}$, hematoxylin and eosin

Reo3, reovirus serotype 3

IFA, immunofluorescence assay

CCI, cell culture isolation

pfu, plaque-forming unit

Children with EHBA constitute the single largest entity of pediatric liver disease requiring transplantation (1). Whereas

Received June 24, 1992: accepted November 23, 1992

Correspondence and reprint requests: Dr. Marie Riepenhoff-Talty. Division of Infectious Diseases, Children's Hospital, 219 Bryant St.. Buffalo, NY 14222

Supported in part by Grant 2723 from the Women's and Children's Health Research Foundation of Buffalo. approximately $15 \%$ of infants with EHBA may have an associated developmental anomaly, the remaining 80 to $85 \%$ have no associated malformations (2). An etiology for the majority of affected infants has not been established. An infectious cause, particularly a perinatal viral infection, has been suggested, and a number of viral pathogens have been ruled out $(3,4)$. Reo3 has been implicated in animal and human studies, but to date. definitive evidence has been difficult to obtain $(5,6)$. Sokol et al. (7) have recently reported an inability to detect Reo3 in liver and bile duct samples from infants with EHBA when these samples were subjected to Reo3-specific polymerase chain reaction. Group A rotaviruses, previously considered strict enterotropic pathogens and the most important cause of infantile diarrhea, have been shown capable of extraintestinal spread to the liver, producing hepatitis in infant mice (8). Extraintestinal spread of group A rotavirus has also been described in immunodeficient children $(8 \mathrm{a})$.

In the present investigation, two hepatotropic strains of group A rotaviruses were investigated for their ability to grow in the cells of the extrahepatic biliary system in infant mice. This work has become increasingly relevant because of our recent preliminary report of group $\mathrm{C}$ rotavirus RNA detected by polymerase chain reaction in two human infants with EHBA (9). Group C rotaviruses, antigenically distinct from group A rotaviruses, have been shown to account for a very small proportion of rotavirus diarrhea in humans but to have worldwide distribution (10-12). These viruses may be more important veterinary diarrheal pathogens, particularly in pigs and possibly in cattle. Antibodies to porcine group $\mathrm{C}$ rotavirus have been found in many adult pigs (13). However, our attempts to infect infant mice with porcine group $\mathrm{C}$ rotavirus have been unsuccessful to date.

\section{MATERIALS AND METHODS}

Animals. Adult male and female BALB/c mice were purchased from rotavirus-free colonies of Charles River Breeding Laboratories, Inc. (Portage, MI). Breeding pairs were housed in microisolator cages in laminar flow hoods. Food and bedding for all mice were sterilized before use. BALB/c mice were tested periodically for antibodies to rotavirus by an enzyme immunoassay. One hundred-twenty pups in 24 litters were used for these studies

Viruses. The HCR-3 stain of serotype 3 human rotavirus was isolated from an asymptomatic child in Philadelphia (HF Clark, unpublished data). It was adapted to cell culture with the aid of trypsin, passaged three times, and plaque-purified in MA104 
cells. For the present studies, it was used at a titer of $1 \times 10^{4}$ $\mathrm{pfu} / \mathrm{mL}$. RRV strain MMU18006, also a serotype 3 rotavirus, was acquired from H. Greenberg (Stanford University and V. A. Medical Center. Palo Alto, CA). RRV was grown in MA 104 cells and was used at a titer of $1 \times 10^{9} \mathrm{pfu} / \mathrm{mL}$. Human rotavirus strain WI-78 was isolated from the stool of a child with diarrhea and adapted to cell culture MA 104 cells (14). It was determined to be a serotype 3 rotavirus by plaque reduction neutralization. This virus was used at a titer of $4 \times 10^{8} \mathrm{pfu} / \mathrm{mL}$. Two-d-old animals were inoculated orally or intraperitoneally with a $10-\mu \mathrm{L}$ volume containing $10^{7}$ pfu of HCR-3, RRV, $4 \times 10^{6}$ WI-78, or cell culture media (placebo)

Clinical assessment. The animals were assessed daily pi for diarrhea and for the appearance of bilirubinuria, acholic stools. and icterus in non-fur-covered areas. The presence of bilirubin and urobilinogen in the urine was tested using Chem Strips (Boehringer-Mannheim, Indianapolis, IN). Gross examination of the liver and biliary system of inoculated animals under a dissecting microscope was carried out, and photographs of the hepatobiliary system were taken with the aid of a camera attached to the microscope. Extrahepatic biliary obstruction was confirmed by detection of a physical stricture in any part of the biliary tree. frequentiy seen with associated bailooning of the duct itself or the gallbladder. Further confirmation was provided by histopathologic studies of bile duct sections revealing the absence of a lumen. Neonatal hepatitis was defined by signs of acute and/or chronic inflammation and any other signs of necrosis or fibrosis in the liver. and. similarly, cholangitis was defined by signs of inflammation and fibrosis in the biliary tree.

Infectious virus and viral antigen detection. Groups of mice were killed at regular intervals pi. Livers and bile ducts from experimentally infected animals were excised and homogenized for isolation of infectious virus in cell culture (MA104) monolayers. The viral isolates were identified by PAGE (15). Frozen sections of the liver and bile ducts were studied by immunofluorescence assay for rotavirus antigen as described previously (6). Guinea pig anti-rotavirus serum and fluorescein-conjugated goat anti-guinea pig IgG (Accurate Chemical and Scientific Co., Westbury, NY) were used for these studies. Blocking assays used rabbit anti-rotavirus serum as an intermediate step to determine the specificity of rotavirus antigen staining.

Histopathology. Consecutive sections of liver, gall bladder, and biliary ducts were fixed in formalin and embedded in paraffin and subsequently stained with $\mathrm{H} \times \mathrm{E}$ or Masson's trichrome and used for histopathologic studies.

\section{RESULTS}

Hepatobiliary disease was seen after oral inoculation of either strain HCR-3 in $24 \%$ of animals or RRV in $42 \%$ of infected animals (Table 1). Clinical disease ranged from mild infection in approximately $50 \%$ of symptomatic animals to severe chronic disease in the other $50 \%$. Seventeen percent mortality in icteric animals was seen on average after inoculation of either virus.

Table 1. Hepatobiliary disease after oral inoculation of neonatal $B A L B / c$ mice with different strains of rotavirus

\begin{tabular}{|c|c|c|c|c|c|c|}
\hline \multirow{2}{*}{$\begin{array}{l}\text { Virus } \\
\text { strain }\end{array}$} & \multirow{2}{*}{$\begin{array}{l}\text { Titer/dose } \\
\text { (pfu) }\end{array}$} & \multirow[b]{2}{*}{$n$} & \multicolumn{2}{|c|}{$\begin{array}{l}\text { Clinical } \\
\text { disease }\end{array}$} & \multicolumn{2}{|c|}{ Mortality } \\
\hline & & & $n$ & $\%$ & $n$ & $\%$ \\
\hline HCR-3 & $1.1 \times 10^{9}$ & 38 & $9^{*}$ & 24 & 5 & 13 \\
\hline RRV & $1 \times 10^{9}$ & 62 & $26+$ & 42 & 11 & 21 \\
\hline WI-78 & $4 \times 10^{8}$ & 23 & 0 & 0 & 0 & 0 \\
\hline Control & & 6 & 0 & 0 & 0 & 0 \\
\hline
\end{tabular}

* Four of nine mice had severe disease: icterus, stunting, acholic stools. marked bilirubinuria, and oily hair effect: five of nine had mild clinical svmptoms and no oily hair effect or stunting and had minimal bilirubinuria.

† Twelve of 26 mice had severe disease as described above.
Three icteric animals recovered clinically to the extent that jaundice decreased and feces and urine were nearly normal in color. No evidence of liver or bile duct involvement or mortality was seen in animals inoculated with WI-78 strain of virus or placebo. Similarly, diarrhea was seen 48 to 72 h pi in nearly $90 \%$ of HCR-3- and RRV-inoculated animals but not in WI-78- or placebo-inoculated animals.

Three fourths of liver and biliary tract samples from HCR-3or RRV-inoculated animals were positive for rotavirus within 8 $\mathrm{d}$ after inoculation when tested by $\mathrm{CCI}$ and/or IFA (Table 2). Of the 15 HCR-3-positive liver samples, five were positive by both CCI and IFA; eight were positive by only CCI, and two were positive by only IFA. Two of the six HCR-3-positive bile ducts were positive by IFA and four were positive by CCI. All mice with virus-positive bile duct samples had positive liver samples. Similarly, all 11 of the RRV-infected livers were positive by CCI, and five of those were positive by IFA also. The percentage of samples positive for either virus decreased over time until $14 \mathrm{~d}$ pi, when virus was no longer detected. WI-78- or placeboinoculated animals were not positive for virus.

The gross morphology of the biliary tracts in affected BALB/ c animals demonstrated a wide range of pathology from developing constriction with a paie area of tissue associated with a ballooning duct to a completely obstructed lumen with swollen ducts and gallbladder engorged with concentrated bile. An example of one type of lesion is seen in Figure $1 A$. This micrograph shows the early stages of developing biliary stenosis in an icteric BALB/c pup, $17 \mathrm{~d}$ after RRV inoculation. There were several areas of narrowing proximal and distal to a ballooning in the common bile duct and a slight concentration of bile in the gallbladder. In Figure $1 B$, the obstruction is complete in the distal common bile duct, and the biliary tract and gallbladder are filled with highly concentrated bile.

The histopathology of infected BALB/c pups was characterized by an acute inflammatory process in the bile ducts within a few days after inoculation of either RRV or HCR-3. The first infiltrating cells were mononuclear cells followed by a mixed polymorphous infiltrate. An example of such an infiltrate is seen in a cross-section of the common bile duct from an icteric pup inoculated $10 \mathrm{~d}$ earlier with HCR-3 (Fig. 2A). Compare this $\mathrm{H} \times \mathrm{E}$-stained frozen section with a normal bile duct from an uninoculated pup in Figure $2 \mathrm{~B}$. In the infected pup, most of the columnar epithelium that lined the lumen has been replaced by regenerated epithelium and the duct is edematous and inflamed. The diameter of the lumen has been reduced by approximately one fourth.

Histologic sections of livers from infected animals with BALB/ c controls were examined without clinical data (blinded study). Controls showed only an extramedullary hematopoiesis. Infected animals demonstrated an acute inflammatory infiltrate in the first week after inoculation. A progression of changes, up to 110 $\mathrm{d}$ pi, within the hepatic parenchyma and portal tracts, showed foci of necrosis (viral plaques), large-droplet steatosis, and a portal

Table 2. Rotavirus replication in hepatobiliary tract of $B A L B / C$ mice

No. positive/no, tested (\%)

\begin{tabular}{lclllc}
\cline { 2 - 3 } & \multicolumn{2}{c}{ Liver* } & & \multicolumn{2}{c}{ Bile duct $\dagger$} \\
\cline { 2 - 3 } \cline { 5 - 6 } Virus & $\leq 8 \mathrm{~d}$ pi & $>8 \mathrm{~d} \mathrm{pi}$ & & $\leq 8 \mathrm{~d}$ pi & $>8 \mathrm{~d} \mathrm{pi}$ \\
\hline HCR-3 & $12 / 16(75)$ & $3 / 10(30)$ & & $4 / 5(80)$ & $2 / 5(40)$ \\
RRV & $10 / 13(77)$ & $1 / 7(14)$ & & NT $\ddagger$ & $0 / 1$ \\
WI-78 & $0 / 5(0)$ & $0 / 5(0)$ & & NT & NT \\
Control & $0 / 3(0)$ & $0 / 3(0)$ & & NT & NT
\end{tabular}

* Of 26 positive liver samples, 10 were positive by CCI and by IFA, 14 were positive by CCI only, and two were positive by IFA only.

$\dagger$ Of six positive bile duct samples, four were positive by $\mathrm{CCI}$ and two were positive by IFA.

$\ddagger$ NT, not tested. 

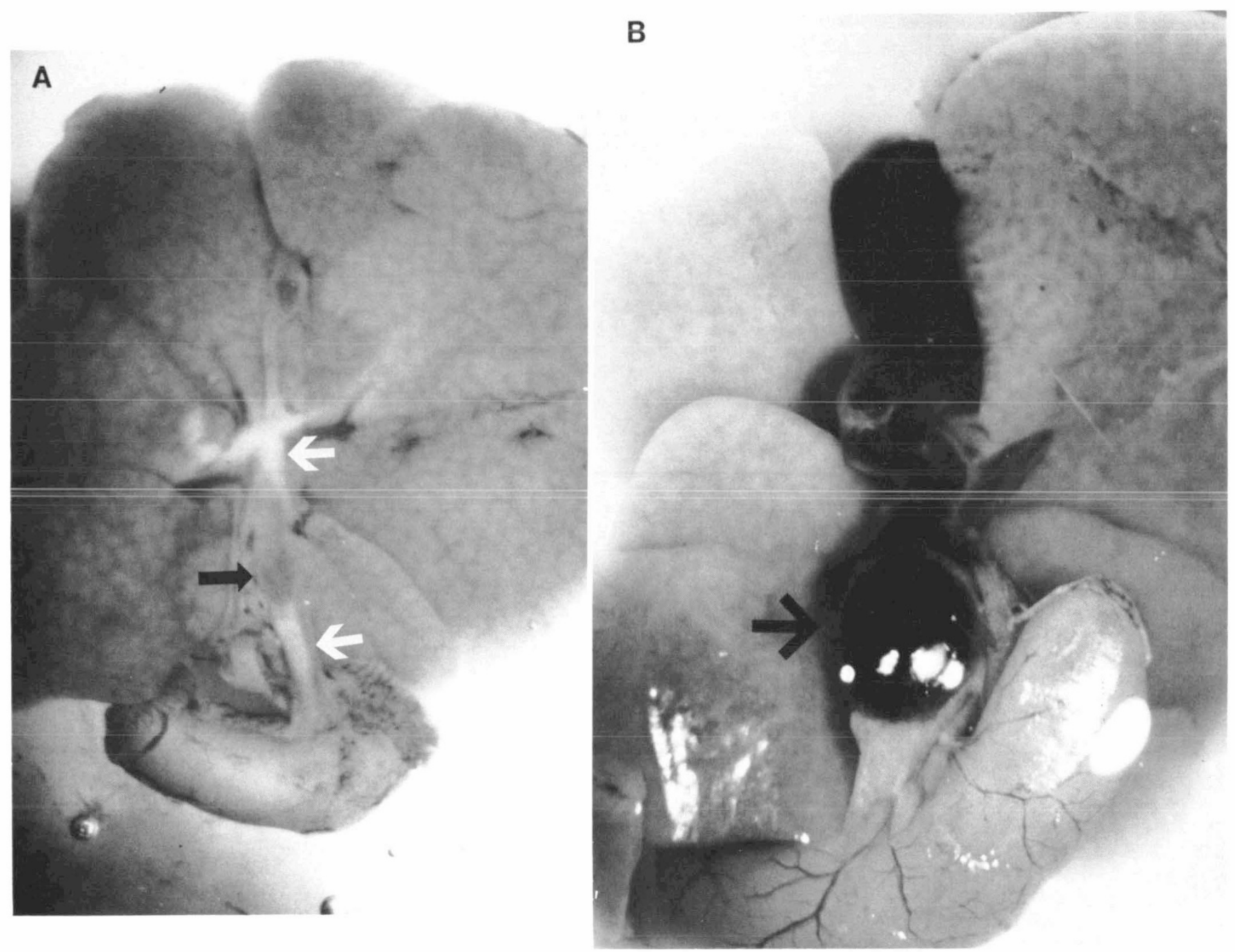

Fig. 1. A, Liver, biliary tract, and portion of the duodenum from an icteric BALB/c pup $17 \mathrm{~d}$ after inoculation with RRV. White arrows, areas of constriction; black arrow, an area of ballooning $(\times 25)$. B. Liver, biliary tract, and duodenal section from an icteric pup with acholic stools $25 \mathrm{~d}$ pi. Black arrow, large, swollen, bile-filled gallbladder $(\times 25)$.

hepatitis varying from a mixed (acute and chronic) inflammatory infiltrate to a chronic type. Within macrophages in portal areas, there was bile deposition. Late changes, beginning at approximately $30 \mathrm{~d}$ pi, showed bile ductule proliferation (neocholangioles) with an acute or chronic cholangiolitis and bridging fibrosis. No bile plugs were noted in bile ductules. The appearance of the liver from an RRV-infected BALB/c pup $30 \mathrm{~d}$ after inoculation is seen in Figure $3 A$. This photograph shows a greatly expanded portal tract. The most significant finding is the presence of a prominent bile ductular proliferation with a mixed inflammatory infiltrate interspersed. A central vein and surrounding liver appear unremarkable. Figure $3 B$ shows a liver section (same magnification) from a 10 -wk-old human infant with biliary atresia. There are portal tracks similar to those in Figure $3 A$ containing neocholangioles and an inflammatory infiltrate. Bridging fibrosis is also readily seen in this figure.

\section{DISCUSSION}

The present report describes two strains of group A rotavirus, one of human origin and one of animal origin, that have hepatobiliary tropism in mice. This is an unusual characteristic in a group of viruses that are strict intestinal pathogens and the major cause of infantile diarrhea $(16,17)$. Human rotavirus HCR-3 and simian rotavirus RRV frequently induced neonatal hepatitis, cholangitis, and occasionally complete biliary obstruction in infant mice after oral inoculation. The clinical disease ranged from completely asymptomatic to fatal infection. However, virus replication was detected in the hepatobiliary system of nearly $90 \%$ of inoculated mice in the first $5 \mathrm{~d}$ after infection. To date, of additional strains tested, only one other group A rotavirus, simian strain SA-11, also a serotype 3 rotavirus like RRV and HCR-3 (18), has been shown to have hepatopathogenic potential in mice (6). Studies of group A rotavirus growth in a human liver cell line (HEpG2) have recently been reported $(19,20)$. Rhesus rotavirus, SA-11, and their single gene substitution reassortants (VP7 from a human parent) were the only viruses that attained titers above input virus (19) or produced significant levels of viral antigen in liver cell cultures (HEpG2) (20). A recent report documenting rotavirus replication in liver and kidney tissue of immunocompromised children warrants followup.

Previous descriptions of hepatopathogenic potential of group A rotaviruses in mice have concentrated on hepatitis (6). The studies described here further expand the tropism of these rotaviruses to include the biliary tract as well as the liver. Many viral infections in mice involve the liver, but viral replication in the bile ducts is rare. Reo3, originally termed hepatoencephalomyelitis virus (21), is one of the few viruses that has been shown to replicate in the biliary tract of mice (22). Reo3 has been impli- 

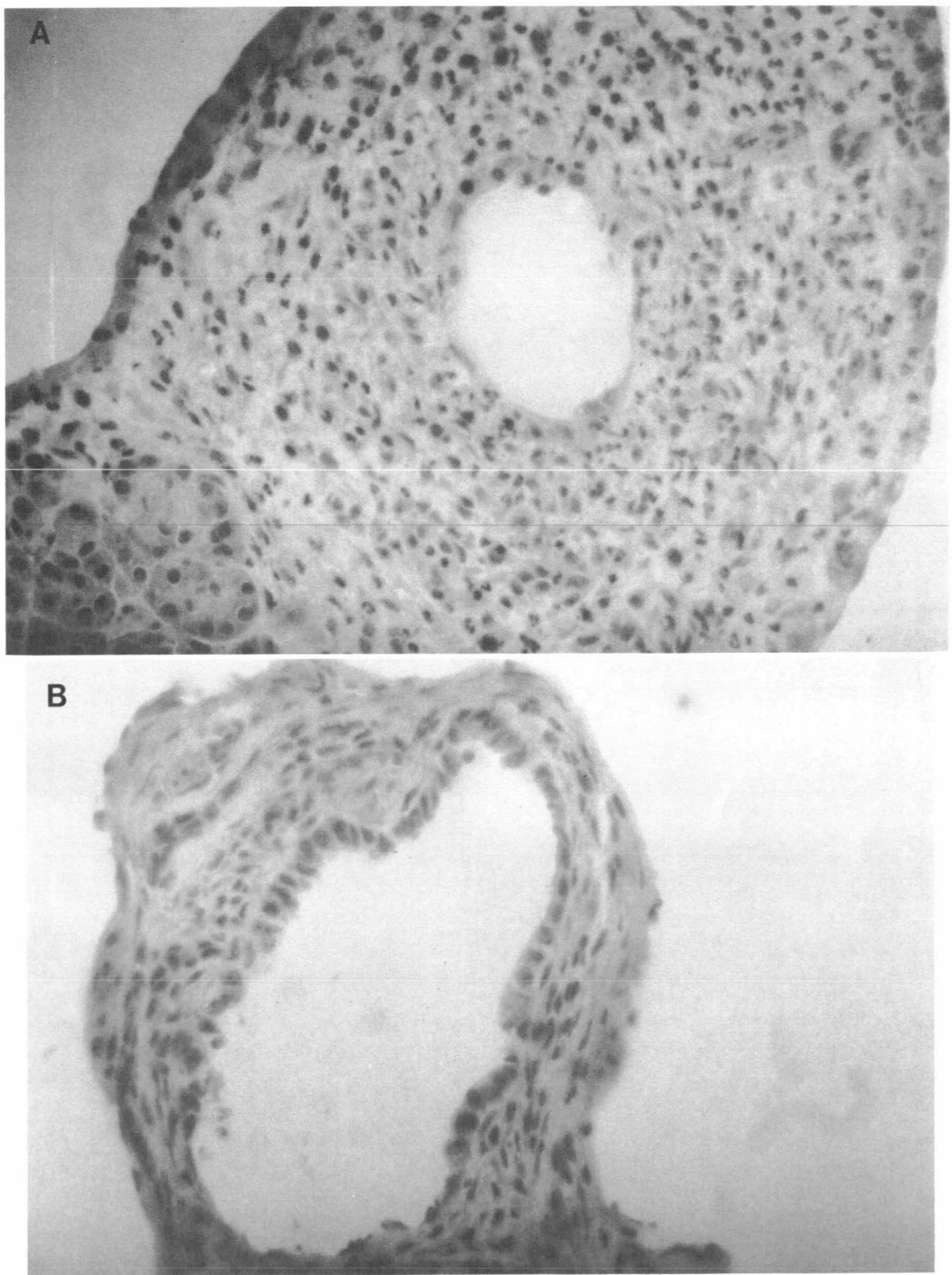

Fig. 2. A, H×E-stained frozen section of the common bile duct from a 12 -d-old BALB/c pup $10 \mathrm{~d}$ after oral inoculation of $\mathrm{HCR}-3(\times 200)$. $B$, $\mathrm{H} \times \mathrm{E}$-stained cross-section of a normal bile duct from a 12-d-old BALB/c control pup $(\times 200)$.

cated as the causative agent of EHBA based on studies in humans as well as in mice $(23.24)$. Both reovirus-induced cholangitis in weanling mice and rotavirus-induced cholangitis in neonatal mice show many of the inflammatory stages seen in affected human infants. However, the obliterative fibrotic lesions, the hallmark of the human disease, were only seen with rotavirus infection. In the reovirus-infected mouse, these lesions were transient or segmental (24). Recently, evidence from human studies has failed to confirm a relationship of Reo 3 to human EHBA $(25,26)$

The proposed model of group A rotavirus-induced extrahepatic biliary obstruction was similar to human EHBA in its 


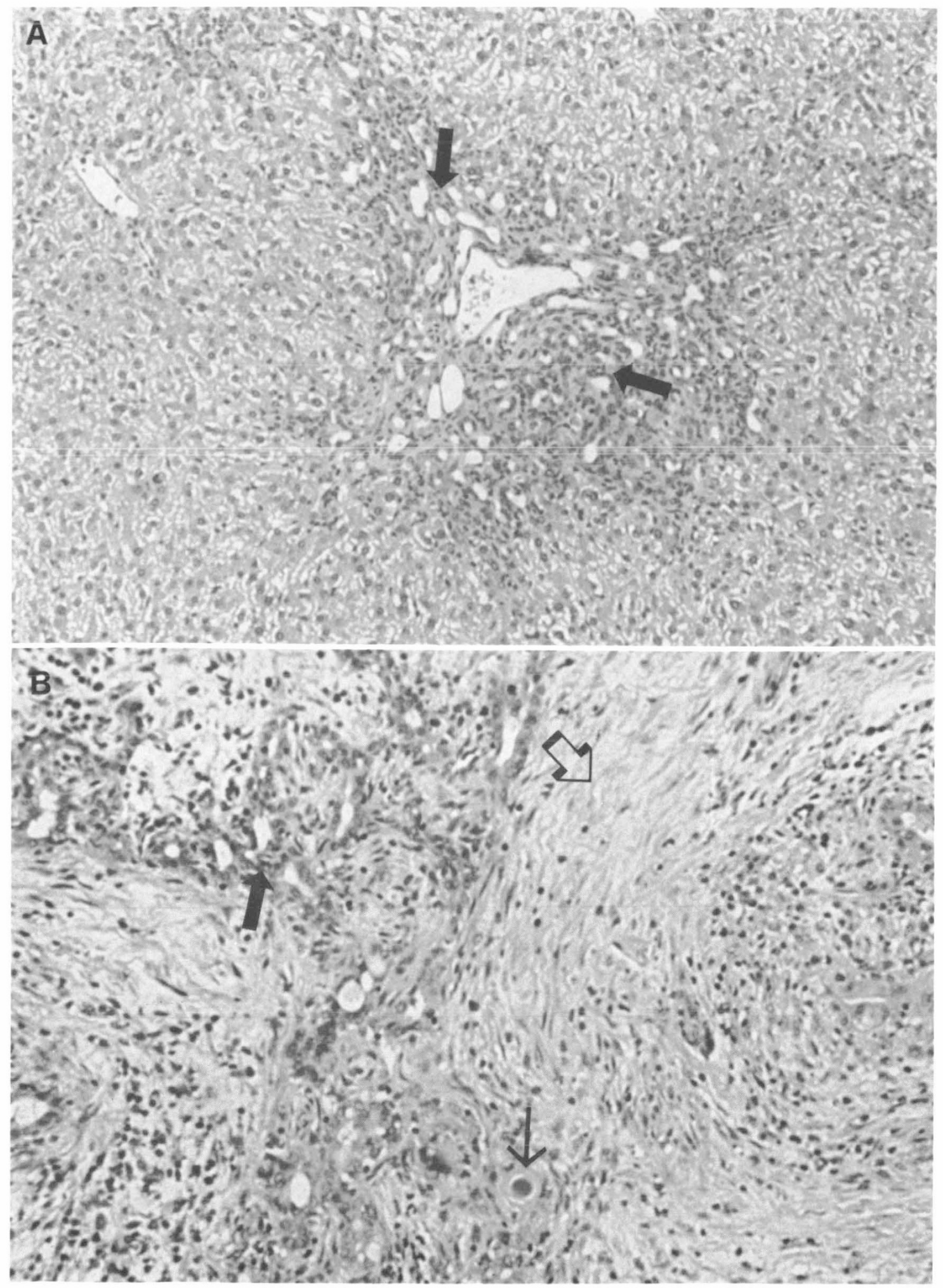

Fig. 3. A, Extrahepatic biliary obstruction (liver from 32-d-old BALB/c mouse). Central portal triads with bile ductular proliferation (arrows) $(\mathrm{H} \times \mathrm{E} \times 100) . B$, Extrahepatic biliary atresia (liver from 10-wk-old human female). Bile ductular proliferation (thick black arrow), bile plug (thin black arrow), and prominent bridging fibrosis (open arrow) $(\mathrm{H} \times \mathrm{E} \times 100)$.

occurrence in neonates, in its comparable clinical symptoms with a chronic irreversible course in nearly half of affected animals, and in histopathologic changes in the liver. In addition, there was a spectrum of clinical disease from mild hepatitis to fatal chronic biliary disease including choledochal cyst in the animal model that reminded us of Landing's hypothesis, which suggests that neonatal hepatitis, choledochal cyst, and biliary atresia are all manifestations of infantile obstructive cholangiopathy with a single disease process (3). One obvious difference was the occurrence of obstruction of bile ducts in the murind model rather than the thread-like bile duct obliteration associated with biliary atresia in human infants. The lesions in the mouse included stenosis and ballooning, primarily of the common bile duct. The gallbladder was nearly always intact and generally 
engorged with bile. However, disease was not always chronic. and a small proportion of mice recovered clinically. In human infants with biliary atresia, the more virulent disease of the biliary tree and the panductular (intrahepatic and extrahepatic) nature of the disease result in the inexerable progression of disease in $100 \%$ of untreated infants with EHBA. One factor that could mediate the difference in severity of disease between human infants and mice is the relative immaturity of the hepatobiliary system in the human neonate compared with the newborn mouse. In addition, the virus itself, if a virus is the cause, is undoubtedly different. In the animal model, the simian and human group A rotaviruses used are heterologous to the murine system. On the contrary, the putative virus producing EHBA in infants would be a human virus and homologous to the human infant.

An important association of rotaviruses with hepatobiliary disease may be the recent preliminary report describing the finding of group $\mathrm{C}$ rotavirus RNA in liver biopsy samples from two infants with extrahepatic biliary atresia. In addition, in these unpublished studies, both infants with EHBA demonstrated specific antibodies to group $C$ rotavirus in convalescent serum samples as measured hy immune electron microscopy. All attempts to find group A rotavirus in samples from the two infants with EHBA were negative. However, these human studies are still preliminary, and a concerted effort is being made to test additional fresh liver biopsy samples from EHBA patients. In the meantime, the group A rotavirus mouse model of biliary disease can be very useful to answer questions of pathogenesis and to explore prevention and treatment modalities. It remains to be seen if group A rotaviruses will be shown to be associated with cases of human biliary atresia; nonetheless, strategic experiments with hepatotropic group A rotaviruses in animals can yield valuable information.

Acknowledgments. The authors thank Helen Barrett. Delmia Ruffin, and Chris Klemenich for excellent technical assistance.

\section{REFERENCES}

1. Jaffe R. Yunis EJ 1985 Pediatric liver transplantation: diagnostic pathology In: CR Abramowsky. RB Colvin (eds) Organ Transplantation in Children Karger, New York. pp 44-81

2. Witzleben CL 1979 Extrahepatic biliary atresia: concepts of cause, diagnosis. and management. In: Perspectives in Pediatric Pathology, Vol 5. Masson Publishing USA Inc.. New York

3. Balistreri WF 1985 Veonatal cholestasis. J Pediatr 106:171-184

4. Landing BH 1974 Considerations of the pathogenesis of neonatal hepatitis. biliary atresia and choledochal cyst: the concept of infantile obstructive cholangiopathy. Prog Pediatr Surg 6:113-139
5. Morecki R. Glaser JH. Cho S. Balistreri WF. Horwitz MS 1982 Biliary atresia and reovirus type 3 infection. N Engl J Med 307:481-484

6. Glaser JH. Balistreri WF. Morecki R 1984 Role of reovirus type 3 in persistent infantile cholestasis. J Pediatr 105:912-915

7. Sokol RJ 1991 American Association for the Study of Liver Diseases Annual Meeting. Chicago, November, abstract

8. Uhnoo I. Riepenhoff-Taltv M. Dharakul T. Chegas P. Fisher J. Greenberg HB. Ogra PL 1990 Extramucosal spread and development of hepatitis in immunodeficient and normal mice infected with rhesus rotavirus. J Virol 64:361368

8a. Gilger MA. Matson DO. Conner ME. Rosenblatt HM. Finegold MJ. Estes MK 1992 Extraintestinal rotavirus infections in children with immunodeficiency. J Pediatr 120:912-917

9. Riepenhoff-Talty M. Gouvea V. Ruffin D. Barrett H. Rossi T 1992 Group C rotavirus (RV): one possible cause of extrahepatic biliary atresia (EHBA) in human infants. Pediatr Res 31:115A(abstr)

10. Bridger JC. Pedley S. MacCrae MA 1986 Group C rotaviruses in humans. J Clin Microbiol 23:760-763

11. Penaranda ME, Cubitt WD. Sinarachatanant P. Taylor DN, Likanonsakul S. Saif L. Glass RI 1989 Group C rotavirus infections in patients with diarrhea in Thailand. Nepal, and England. J Infect Dis 160:392-397

12. von Bonsdorff $\mathrm{CH}$. Svensson L 1988 Human serogroup $\mathrm{C}$ rotavirus in Finland. Scand J Infect Dis 20:475-478

13. Bridger JC. Brown JKF 1985 Prevalence of antibody to typical and atypical rotavirus in pigs. Vet Rec 116:50

14. Bell LM. Clark HF. O’Brien EA. Kornstein MJ. Plotkin SA. Offit PA 1987 Gastroenteritis caused by human rotaviruses (serotvpe three) in a suckling múse mudel. Proc Soc Exper Biol Mcd 184:127-132

15. Clark HF. Dolan KT, Horton-Slight P, Palmer J, Plotkin SA 1985 Diverse serologic response to rotavirus infection of infants in a single epidemic. Pediatr Infect Dis 4:626-631

16. Cukor G. Blacklow NR 1984 Human viral gastroenteritis. Microbiol Rev 48:157-179

17. Kapikian AZ, Chanock RM 1990 Rotaviruses. In: Fields BN. Knipe DM (eds) Virology, 2nd ed. Raven Press. New York, pp 1353-1404

18. Riepenhoff-Talty M. Uhnoo I. Greenberg HB. Vo P. Clark HF. Fisher JE Ruffin D. Barrett H 1992 Hepatopathogenic potential of rotaviruses. Abstracts of the General Meeting of the American Society for Microbiology, May 1992. pp 408(abstr T2)

19. Ramig RF, Galle KL 1990 Rotavirus genome segment 4 determines viral replication phenotype in cultured liver cells (HepG2). J Virol 64:1044-1049

20. Schwarz KB. Moore TJ. Willoughby RE Jr. Wee SB. Vonderfecht SL. Yolken RH 1990 Growth of group A rotaviruses in a human liver cell line. Hepatology 12:638-643

21. Stanley NF. Dorman DC. Ponsford J 1953 Studies on the pathogenesis of a hitherto undescribed virus (hepato-encephalomyelitis) producing unusual symptoms in suckling mice. Aust J Exp Biol 31:147-160

22. Phillips PA. Keast D. Papadimitriou JM, Walters MN-I, Stanely NF 1969 Chronic obstructive jaundice induced by reovirus type 3 in weanling mice. Pathology 1:193-203

23. Glaser JH, Morecki R 1987 Reovirus type 3 and neonatal cholestasis. Semin Liver Dis 7:100-107

24. Bangaru B, Morecki R. Glaser JH, Gartner LM. Horwitz MS 1980 Comparative studies of biliary atresia in the human newborn and reovirus-induced cholangitis in weanling mice. Lab Invest 43:456-462

25. Brown WR. Sokol RJ. Levin MJ. Silverman A. Tamaru T. Lilly JR. Hall RJ. Cheney M 1988 Lack of correlation between infection with reovirus 3 and extrahepatic biliary atresia or neonatal hepatitis. J Pediatr 113:670-676

26. Brown WR 1990 Lack of conformation of the association of reovirus 3 and biliary atresia: methodological differences. Hepatology 12:1254-1255 